\title{
A INTELIGÊNCIA EMOCIONAL: INFLUÊNCIA NA VIDA PROFISSIONAL E NAS ORGANIZAÇÕES
}

\author{
Israel Ribeiro Alves ${ }^{1}$
}

RESUMO: Apresente artigo possui como objetivo verificar através de pesquisa bibliográfica além de artigos e dissertações sobre o tema, afim de demonstrar a aplicação da inteligência emocional no ambiente organizacional, através do desenvolvimento das lideranças, com o conceito de inteligência emocional, tendo em vista como as pessoas se comportam comunicam-se, e como se relacionarem no ambiente organizacional, consequências sofridas pela organização por atitudes, casadas pela tomada de decisões e negociações baseadas no uso das emoções, e a importância do uso inteligente e adequado das emoções para a geração de resultados positivos. O seu conceito agregado ao cotidiano ressalta os pontos essenciais que tornam o indivíduo mais ativo e passível à obtenção de sucesso. Busca-se verificar o crescimento do profissional proporcionando a valorização dos envolvidos no constante processo de desenvolvimento. Objetiva-se compreender como ela influencia no ambiente organizacional além de identificar habilidades e competências e enfatiza a importância do ambiente saudável. O conhecimento dos conceitos da inteligência emocional é de suma relevância para que a organização saiba reconhecer e promover o indivíduo, uma vez que num ambiente equilibrado os profissionais motivados são mais propícios ao crescimento resultando, consequentemente, na eficiência da prestação de serviços.

Palavras-Chave: Ambiente Organizacional. Inteligência Emocional. Competências.

ABSTRACT: This article aims to verify through bibliographical research, in addition to articles and dissertations on the subject, in order to demonstrate the application of emotional intelligence in the organizational environment, through the development of leaders, with the concept of emotional intelligence, in view of how the people behave, communicate, and how to relate in the organizational environment, consequences suffered by the organization for attitudes, coupled with decision-making and negotiations based on the use of emotions, and the importance of the intelligent and appropriate use of emotions to generate results positive. Its concept added to everyday life highlights the essential points that make the individual more active and likely to achieve success. It seeks to verify the professional's growth, providing the appreciation of those involved in the constant development process. The objective is to understand how it influences the organizational environment in addition to identifying skills and competences and emphasizes the importance of a healthy environment. Knowledge of the concepts of emotional intelligence is of paramount importance for the organization to know how to recognize and promote the individual, since in a balanced environment, motivated professionals are more conducive to growth, resulting, consequently, in the efficiency of service provision.

Keywords: Organizational. Environment. Emotional Intelligence. Skills.

\footnotetext{
I Administrador e consultor com registro no CRA-SC 28764, graduado no curso de administração de empresas pela Faculdade de Ciências Administrativas e Contábeis, Centro Universitário da Grandes Dourados, UNIGRAN. Pós-graduação em MBA executivo em administração com ênfase em recursos humanos, Centro Universitário da grandes dourados, UNIGRAN. Cursando mestrado em administração, pela Must University (Florida- USA).
} 


\section{INTRODUÇÃO /METODOLOGIA}

Este paper apresenta pesquisa investigativa através de websites, e bibliografia, por meio de artigos com o tema sobre a inteligência emocional alta ou baixa, há vários tipos de personalidades que o ser humano dispõe, como sentimentos, e emoções distintas uma das outras, em razão do avanço tecnológico que está em constante crescimento, o qual tem causado intensa competividade no mercado, com constante mudanças no ambiente organizacional.

E cabe ao líder exercer importante papel, para que possa identificar todas as emoções de cada subordinado, e então controlá-la de forma eficaz e saudável, para não atrapalhar o desempenho da função e problemas sem gerar conflitos, a Inteligência Emocional corretamente administrada, surte efeito positivo na equipe de trabalho grande valia, levando a organização ao sucesso. $O$ líder que conhece os seus colaboradores, os entendendo e se pondo no lugar deles gera mais empatia, com isso pode verificar o porquê de o trabalho muitas vezes não estar surtindo efeitos positivos, tendo quedas na produtividade, que na maioria das vezes está ligado intimamente com o emocional desiquilibrado do colaborador por estar passando por problemas de relações pessoais ou familiar, e por fim estar resultando em problemas em desempenho de sua função no trabalho.

Portanto, com a administração correta dessas emoções pode se entender melhor cada colaborador, e aprimorá-los, gerenciando o capital intelectual para o melhor crescimento pessoal e profissional, assim elencando maiores benefícios para a organização que dispõe de uma equipe preparada.

\section{DESENVOLVIMENTO - REVISÃO DE LITERATURA}

\section{CONTROLE EMOCIONAL}

O controle emocional proporciona mudanças significativas transformando o ambiente profissional e familiar, através do conhecimento consciente de suas responsabilidades e também sobre o seu bem-estar e de outros.

De acordo com (GOLEMAN, 2007). A pessoa pode controlar suas emoções e saber usá-las de forma inteligente, acaba mudando muita coisa em suas atitudes, 
decisões e aprende a entender outras pessoas mais claramente, com o uso das habilidades adquiridas para promover uma mudança cultural e social no meio em que vive ou trabalha.

Conforme (GIROTTO, 2008). A Inteligência Emocional (I.E.) é a capacidade de perceber e exprimir a emoção, assim como assimilá-la, compreendê-la, raciocinar com ela e saber regulá-la em si e nos outros.

$\mathrm{O}$ indivíduo quando orientado sobre o uso das emoções de maneira inteligente, para que haja equilíbrio entre a emoção e razão ao lidar com conflitos adversos, relacionado a pessoas, seja no contexto profissional ou no pessoal, gerando resultados positivos para o indivíduo no meio em que está inserido, proporcionando o desenvolvimento para o crescimento individual.

Conforme (OLIVEIRA, 2010). As emoções sendo bem conduzidas aperfeiçoam as chances de uma vida bem sucedida, possibilitando ao indivíduo absorver novos conhecimentos, melhorar o relacionamento interpessoal e intrapessoal, aumentar a produtividade, elevar a autoestima, a automotivação e assim conseguir transferir às pessoas com as quais se relaciona sensações e sentimentos positivos, proporcionando benefícios através da Inteligência Emocional.

Portanto um indivíduo motivado vê pontos positivos tanto de situações favoráveis como desfavoráveis, e visualiza soluções para os problemas e não vê somente os seus entraves, que ao relacionar-se com pessoas mal humoradas, pessimistas que não visam horizontes, transferindo a elas sensações positivas, tornando-se referência estimulando-as a mudarem o comportamento e as atitudes, transformando-as em pessoas equilibradas e felizes.

\section{INTELIGÊNCIA EMOCIONAL}

De acordo com (WEISINGER, 200I). A inteligência emocional é simplesmente o uso inteligente das emoções, isto é, fazer intencionalmente com que suas emoções trabalhem a seu favor, usando-as como uma ajuda para ditar seu comportamento e seu raciocínio de maneira a aperfeiçoar seus resultados, portanto inteligência emocional não e ser apenas simpáticos, ou então falar tudo o que está ligado ao seu pensamento, e 
sim ter autocontrole das emoções, e expressá-los de forma adequada administrando os sentimentos, permitindo um ambiente de trabalho produtivo e tranquilo, afim de que o sucesso alcançando de acordo com as metas.

De acordo com (GOLEMAN, 2007). As emoções orientam a nossa navegação pelas nossas deliberações [...] a chave para tomar boas decisões pessoais é ouvir os sentimentos, segundo o autor, precisamos desenvolver dois conjuntos de competências, as Competências Pessoais como Habilidades Intrapessoais e Competências Sociais como Habilidades Interpessoais.

Indivíduos com a inteligência emocional bem desenvolvida têm extrema facilidade de adaptação à dinâmica organizacional, integração e relacionamento, pois são comunicativas e criativas, e possuem um forte sentido de responsabilidade e uma capacidade notável de adaptação à mudança.

O desenvolvimento desta capacidade faz com que as pessoas consigam ser imparciais, transpassando harmonia para a equipe e direcionando o esforço de todos para os objetivos organizacionais com sucesso.

\section{I LIDERANÇA E INTELIGÊNCIA EMOCIONAL}

A relação estabelecida direta com colaboradores com as mais diferentes personalidades com as metas da organização, e para que o líder consiga ter um desempenho bom de sua equipe, torna-se necessário o aperfeiçoamento da sua inteligência emocional.

As emoções quando são administradas adequadamente permitem que aumente a produtividade, um bom relacionamento, geram mais lealdade e comprometimento com o trabalho além do bem-estar, auxiliando na resolução de conflitos. Conforme (GOLEMAN, Inteligência emocional, 2012). A emoção não é apenas importante, mas absolutamente necessária para a tomada de boas decisões, otimização na solução de problemas, mudanças e assim, o alcance do sucesso.

Os líderes exercem grande influência no seu ambiente de trabalho os gestores representam um modelo para a sua equipe, sendo que a criatividade e a liberdade individual são recursos essenciais para uma organização, pois eles podem ajudar a 
desenvolver isso em outros colaboradores podendo manter uma ideia clara do que podem realizar e de que querem ser.

\section{A IMPORTÂNCIA DA MANUTENÇÃO DO CLIMA ORGANIZACIONAL NA EMPRESA}

Habilidades cada vez mais desenvolvidas emocionalmente é o que as organizações buscam em seus profissionais, elas têm o importante papel para realização do clima organizacional das empresas em sua manutenção, atreves de práticas adotadas para incentivar da sua equipe o seu desenvolvimento, a empresa deixa claro para aos seus membros, sua cultura organizacional, e valores, promovendo treinamentos para desenvolvimento de habilidades e emocionais, de acordo com o cargo dos trabalhadores e suas responsabilidades, com o intuito de integrá-las, orientando e ouvindo-as, sendo que, estas práticas e ações auxiliam na manutenção do clima organizacional estimulando um clima organizacional aceitável.

O ser humano tem a necessidade de ter o seu reconhecido e também aceito pelo grupo em que está inserido, tanto no ambiente de trabalho, e em outros lugares, expressando o desejo de participar, e de perceber que a organização importasse com ele o reconhece e valoriza o seu trabalho.

Para isso e a atribuída à empresa a importância da manutenção do seu clima organizacional, de acordo com (OLIVEIRA, 2010). Se o clima for receptivo, amigável, quente e agradável todos os participantes da organização estarão à vontade para exercer de maneira satisfatória o seu trabalho, fazendo com que a empresa conquiste a confiança dos seus integrantes, fazendo com que executem melhor suas atividades a cada dia.

A empresa deve incentivar os colaboradores motivacionalmente a alcançarem um alto nível de produtividade, mostrando a importância de trabalho coletivo, evitando o clima for negativo, adverso, frio e desagradável, pois pode fazer com que os colaboradores não permaneçam na organização, e em consequência estará propenso a o absenteísmo, rotatividade de pessoal, reduzindo a produtividade, prejudicando a qualidade do trabalho, e impactando no custos trazendo prejuízos para o seu crescimento e frente ao mercado. 
As pessoas não agem sempre da mesma forma mesmo que em situações semelhantes, e o comportamento do indivíduo está condicionado ao clima, e cada um reage de uma maneira diferente, e cabe o gerenciamento e a manutenção do clima organizacional através dos líderes da organização, garantir a satisfação do grupo no trabalho.

O líder tem o dever de manter o clima organizacional favorável junto com a organização, e uma vez que após serem treinados e capacitados são responsáveis por gerenciar os conflitos e administrar as emoções de sua equipe, participando e acompanhando o seu desenvolvimento, e o bom desempenho.

Sendo que organização tem um papel importante, que é divulgar claramente para todos os seus integrantes, seus valores, a sua cultura organizacional, promovendo treinamentos para o desenvolvimento de habilidades emocionais, com os colaboradores motivados e incentivados pelo seu supervisor, exercem seu trabalho de maneira satisfatória, com isso, eles geram resultados positivos se tornam mais eficientes para a empresa.

\section{CONCLUSÃO}

O objetivo deste trabalho é contribuir para o esforço contínuo para compreender a importância para o indivíduo e para a empresa em desenvolver a inteligência emocional, neste contexto conclui-se, que o trabalho contribui e agrega maior conhecimento acerca do tema relatados neste artigo, é notável que este tema é ainda pouco explorado no cenário organizacional, e pode ser desenvolvido de modo significativo

Desenvolver inteligência emocional no mundo corporativo é cada vez mais essencial, e é necessário que os profissionais utilizem ferramentas e informações de modo inteligente transformando os sentimentos e as emoções em ações positivas.

Em grande parte, o relacionamento é a capacidade de lidar com as próprias emoções e também as dos outros, é muito importante a inteligência emocional para o âmbito organizacional, pois os integrantes que possuem as habilidades da Inteligência Emocional, tem produtividade maior, um relacionamento melhor e tem a tomada de 
decisões mais assertivas e eficientes, consequentemente melhorando resultados, com menos conflitos e ambientes mais agradáveis.

é importante nas organizações, com controle das emoções, motivação de funcionários com a inteligência emocional, o líder ser inteligente emocionalmente é de extrema importância fazer com que a equipe gere resultados positivos e maior produtividade nos serviços, gestores tomando decisões assertivas, resistir a tensões, otimizar os processos tudo isso é resultado de um líder com inteligência emocional. diminuindo conflitos no ambiente de trabalho.

Portanto, concluo que todas as organizações deveriam se aprofundar no assunto e aplicar em seus membros a Inteligência Emocional, pois empresas são feita de pessoas e essas precisam ser inteligentes emocionalmente, administrando as próprias emoções e entendendo as dos outros, gerando resultados satisfatórios não só para o líder que administrara os conflitos pessoais e profissionais, e sim para a organização que terá eficiência e eficácia com o nível de relacionamento melhor para todos os colaboradores, gestores, e com os membros de sua equipe.

\section{REFERÊNCIAS BIBLIOGRÁFICAS}

GIROTTO, M. (2008). Inteligência Emocional nas Organizações. Trabalho de Conclusão de Curso (Administração de Empresas) . (F. M. IMESA., Ed.) Assis, São Paulo, Brasil. Acesso em 26 de 05 de 2021, disponível em https://cepein.femanet.com.br/BDigital/arqTccs/o711260102.pdf

GOLEMAN, D. (2007). Inteligência emocional. A teoria revolucionária que redefine o que é ser. (OBJETIVA, Ed.) Rio de Janeiro, Rio de Janeiro, Brasil. Fonte: https://lelivros.love/book/baixar-livro-inteligencia-emocional-daniel-goleman-em-pdfepub-e-mobi-ou-ler-online/

GOLEMAN, D. (2012). Inteligência emocional. A teoria revolucionária que define o que é ser. (Objetiva, Ed.) Rio de Janeiro, Rio de Janeiro, Brasil: Objetiva. Acesso em o3 de o6 de 2021, disponível em https://dspace.uniceplac.edu.br/bitstream/123456789/740/r/Yann\%2oRodrigues\%2oSous a_ool2055.pdf

OLIVEIRA, M. (2010). Inteligência emocional nas organizações. estudo de caso. (FEMA, Ed.) Assis, São Paulo, Brasil. Acesso em 28 de 05 de 202I, disponível em https://cepein.femanet.com.br/BDigital/arqTccs/o7ır26oroz.pdf 
WEISINGER, H. (20oI). Inteligência Emocional no trabalho. Como aplicar os conceitos revolucionários da I.E.nas suas relações profissionais, reduzindo o estresse, aumentando sua satisfação, eficiência e competitividade. (Objetiva, Ed.) Rio de Janeiro, Rio de Janeiro, Brasil: Objetiva. Acesso em 02 de 06 de 2I, disponível em https://www.aedb.br/seget/arquivos/artigosil/38814405.pdf. 